\title{
Micro-scale abrasive wear of coated surfaces-prediction models
}

\author{
A. Ramalho* \\ Universidade de Coimbra-FCTUC-Dep. Eng. Mecânica, Pólo II, Pinhal de Marrocos, P-3030 Coimbra, Portugal
}

Received 12 April 2004; accepted in revised form 21 December 2004

Available online 11 April 2005

\begin{abstract}
Micro-scale abrasive wear testing is widely used to characterise thinly coated surfaces. Beyond the several advantages of this technique, the possibility of finding the specific wear rates both for the substrate and for the coating with only one set of tests on coated specimens is certainly an important reason for the rapid spread of the micro-scale abrasive technique. It has not yet been established if the coating and the uncoated substrate can be characterized separately, with the results subsequently being used to calculate the wear characteristics of thincoated surfaces. This paper concerns the development of a model to predict the behaviour of coated surfaces, based on previous characterisation of the coating and of the substrate in non-perforating tests. By comparison with experimental results, the method developed is used to forecast the abrasion resistance of TiN and of thinly coated copper specimens.
\end{abstract}

(C) 2005 Elsevier B.V. All rights reserved.

Keywords: X[B]Micro-scale abrasive test; [B]Wear; [C]Physical vapour deposition

\section{Introduction}

Micro-scale abrasion testing by ball cratering is now a well-established technique for characterising coated and surface-engineered materials. For thin coatings like those deposited by PVD, perforation of the coating occurs after a low number of rotations. Wear evolution is therefore influenced by the effect of both the coating and the substrate. If the intrinsic behaviour of the coating is to be determined, a suitable method must be used to separate the effect of the substrate. The basis for analysing the results to obtain the coating behaviour have been derived by Kassman et al. [1] and successively updated [2-7]. A recent paper by Kusano et al. [8] reviews and discusses the measurement methods and the various procedures for analysing the test results. The aim of all the data-analysis methods is to be able to calculate the intrinsic abrasion resistance of thin coatings by separating the substrate effect and obtain the specific wear rate of both coating and

\footnotetext{
* Tel.: +351 239790756; fax: +351 239790701 .

E-mail address: amilcar.ramalho@dem.uc.pt.
}

substrate. In spite of the differences between several methods, in general, all of them are based on the same fundamental principle: ball cratering is an imposed shape wear test; therefore, the wear depth increases at the same rate in both coating and substrate.

Some analytical methods [1,7] evaluate the uncoated substrate separately to obtain the specific wear rate of the substrate. However, there is no certainty that the behaviour of the substrate evaluated in a separate test is similar to that of the material beneath the tested coating. Another problem related to this approach is the fact that the load distribution between the substrate and the coating changes markedly when the scar is much deeper than the coating thickness. In that case, the approximation to equal wear may be a rough approximation.

The data analysis methods used to calculate the specific wear rate of coating and substrate simultaneously are more often used for coatings harder than the substrates. The aim of the present study is to investigate prediction models for abrasion wear in perforating contacts on thin coatings and the validation of the model by applying them to experimental test results of both hard and soft coatings. 


\section{Theoretical concepts}

In ball-cratering microscale abrasive test, a rotating steel ball is loaded onto the sample. An abrasive slurry is dripped onto the wear interface. After the test is complete, the wear is evaluated by optical measurement of the resulting wear scar. Wear rates are determined by measuring the progressive wear over an extended number of cycles.

Although ball cratering is a general wear test method, it was introduced especially to study thin-coated surfaces. However, the testing of thin coatings usually leads to wear scars through the coating, and a "bulls-eye" depression is seen where the substrate shows through. In general, it is expected that the coating and the substrate exhibit different $k$ values, so the wear behaviour depends on the response of both the coating and the substrate. In a very recent paper, Kusano et al. [8] presents a complete review of the available methods that can be used for the data analysis of micro-scale abrasion of coated substrates.

The response of materials to this test depends on the nature of the motion of the abrasive particles in the contact zone. When the particles roll, the material is removed by multiple indentations and the wear mechanism is called three-body abrasion; but if the particles slide causing grooving, the mechanism is called two-body abrasion. The normal load and the slurry particles content are the main parameters that determine which type of abrasion occurs.

When a perforating test is carried out, a mixed contact occurs. In this case, the wear crater includes a crownshaped part corresponding to the coating and a central, circular area that corresponds to the substrate. The volume values of the wear scar fractions corresponding to the coating and to the substrate were evaluated by measuring the dimensions of the wear scar, Fig. 1. The volume values were calculated using an approach based on the assumption that the radius of the wear scar is equal to the radius of the ball, $R$, on the coating and the substrate alike. Therefore, the total volume removed by wear can be calculated using the approximate Eq. (1). Kusano et al. [8] demonstrated that the simple expression (1) is very accurate and the major source of error, as a rule, is the uncertainty in evaluating the outer scar diameter, $b$. The substrate wear volume can be calculated applying the same expression to the inner part of the crater, Eq. (2). The volume of the scar portion corresponding to the coating can ultimately be achieved by subtracting the volume of the substrate from the total volume, Eq. (3).

$$
\begin{aligned}
& V_{\mathrm{t}}=\pi \frac{b^{4}}{64 R} \\
& V_{\mathrm{s}}=\pi \frac{a^{4}}{64 R} \\
& V_{\mathrm{c}}=V_{\mathrm{t}}-V_{\mathrm{s}}
\end{aligned}
$$

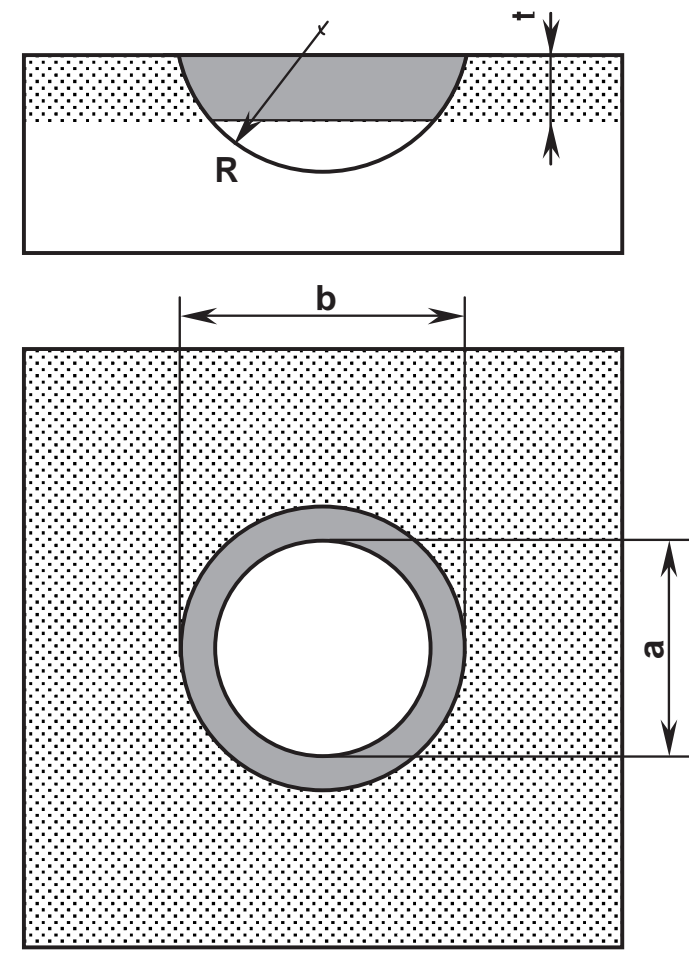

Fig. 1. Schematic diagram of a typical wear scar resulting from the perforating test.

The major inaccuracy of the wear volume calculation using Eqs. (1)-(3) arises from the fact that the outer limit of the wear scar, corresponding to the coating surface, is poorly defined. A particle entering the contact, mainly in threebody abrasion, can pit the limit of the scar and the accurate definition of the scar dimension $b$ is not evident. In many cases, therefore, the total wear volume $V_{\mathrm{t}}$ calculated by Eq. (1) is overestimated, giving values of the coating wear volume $V_{\mathrm{c}}$ higher than the true value. Alternatively, the coating wear volume can be found, considering that both the inner and outer diameters, $a$ and $b$, are sufficiently accurate, and admitting that the radius of the scar could be different from the radius of the ball, Eq. (4), where $t$ is the coating thickness.

$V_{\mathrm{c}}=\frac{\pi}{6} t\left[3\left(\frac{b}{2}\right)^{2}+3\left(\frac{a}{2}\right)^{2}+t^{2}\right]$

Kusano et al. [8] assume that, for coatings with good adhesion to the substrate, the inner diameter can generally be measured more accurately than the outer diameter. They thus proposed an Eq. (5) for calculating the wear volume of the coating, $V_{\mathrm{c}}$, based on the inner diameter, $a$, and the coating thickness, $t$. Eq. (5) considers the equal wear approach and thus assumes the ball radius for the coating scar.

$V_{\mathrm{c}}=\pi t\left[\left(\frac{a}{2}\right)^{2}-\frac{t^{2}}{3}+R t \sqrt{1-\left(\frac{a}{2 R}\right)^{2}}\right]$ 
The Archard wear model, as introduced by Kassman et al. [1], can be applied to the wear of coatings with composite contacts, i.e., wear scars that include areas of both substrate and coating materials, according to Eq. (6),

$S N=\frac{V_{\mathrm{s}}}{k_{\mathrm{s}}}+\frac{V_{\mathrm{c}}}{k_{\mathrm{c}}}$

where $k_{\mathrm{s}}$ and $k_{\mathrm{c}}$ are, respectively, the specific wear rate of the substrate and of the coating. The main differences between the several methods of analysing the results to find the values of $k_{\mathrm{s}}$ and $k_{\mathrm{c}}$ are concerned with how Eq. (6) is arranged to explain the specific wear rates as a function of the wear volumes [8].

Dividing Eq. (6) by $V_{c}$, Allsop [9] derived Eq. (7) that is the bases of a formulation that allow the specific wear rates of both substrate and coating from a single set of data points. From a set of data points, a linear relationship between $\left(S N / V_{\mathrm{c}}\right)$ and $\left(V_{\mathrm{s}} / V_{\mathrm{c}}\right)$ can be obtained. According to Eq. (7), both $k_{\mathrm{s}}$ and $k_{\mathrm{c}}$ could be calculated, respectively, as the inverse of the slope and of the intercept of the linear line fitted to the experimental data points.

$\frac{S N}{V_{\mathrm{c}}}=\frac{V_{\mathrm{s}}}{V_{\mathrm{s}}} \frac{1}{k_{\mathrm{s}}}+\frac{1}{k_{\mathrm{c}}}$

The aim of this paper concerns the establishment of a new prediction criterion that allows forecasts evolution of wear volumes and wear depths, for any coating/substrate arrangement. The prediction criterion is based on the general formulation previously defined assuming that even for perforating tests, the development of the scar is always by imposed shape wear. Thus, the radius of the scar is equal to the ball radius.

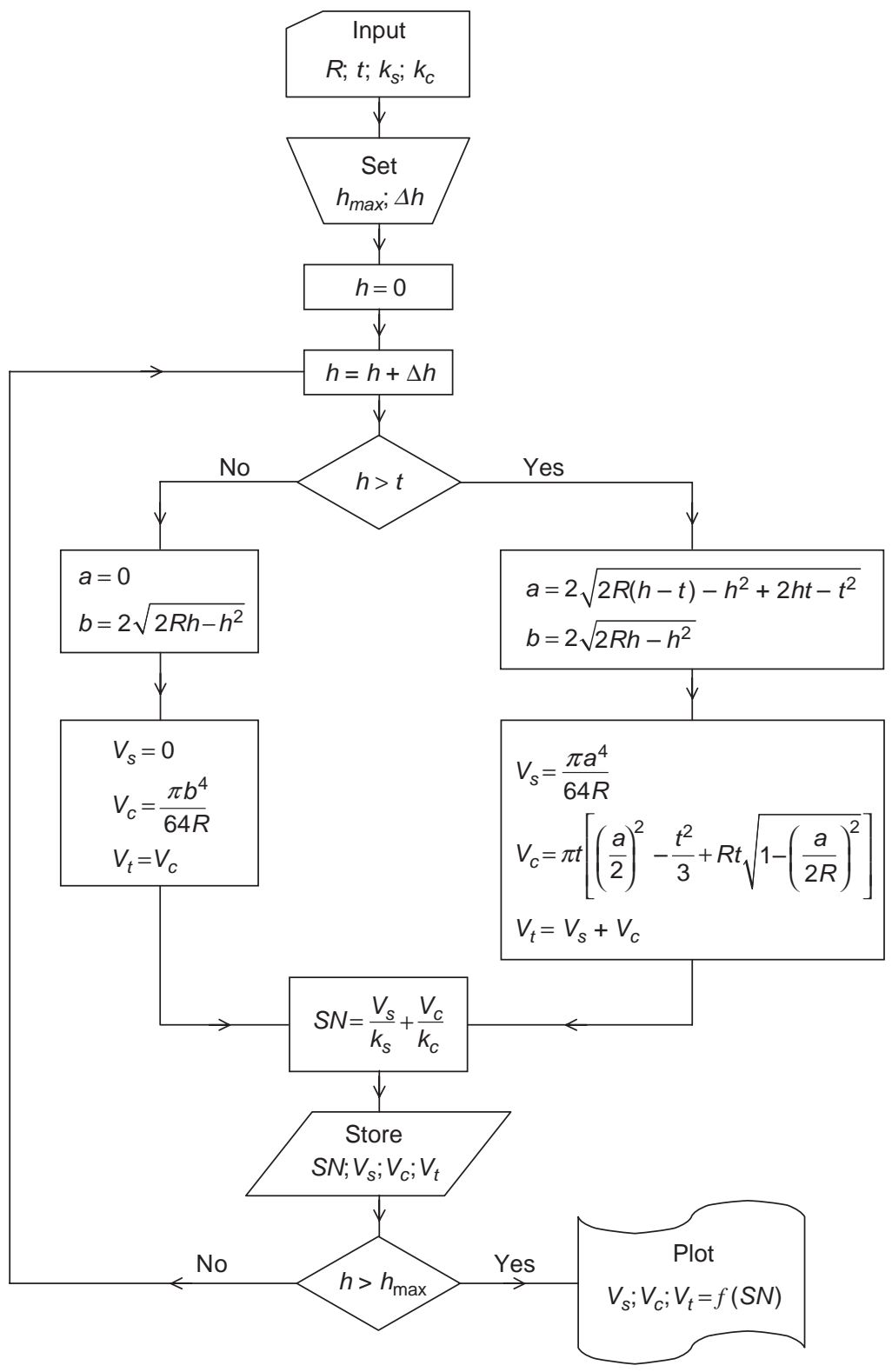

Fig. 2. Flow-chart of the prediction model. 
To apply the prediction model, the thickness of the coating and the specific wear rates $k_{\mathrm{s}}$ and $k_{\mathrm{c}}$ must be clearly defined. Substrate specific wear rate could be obtained testing uncoated substrate whereas the coating wear rate must be obtained by non-perforating low-duration tests. The prediction model is summarised on the flow-chart of Fig. 2 and could be applied step by step according to the following procedure:

(1) select the maximum depth, $h_{\max }$, of the wear scar and the step $\Delta h$ to be used on the analysis;

(2) the prediction criteria starts with a first total depth of the scar, $\Delta h$, that is smaller than the coating thickness, $t$;

(3) assuming that the radius of the scar is equal to the radius of the ball, the values of the scar dimension $b$ can be calculated; $a$ remains zero while $h<t$;

(4) applying Eq. (1), the total wear volume can be achieved, as $h<t V_{\mathrm{c}}=V_{\mathrm{t}}$ and $V_{\mathrm{s}}=0$;

(5) if the specific wear rate has already been found, Eq. (6) allows the value of $S N$ to be calculated;

a)

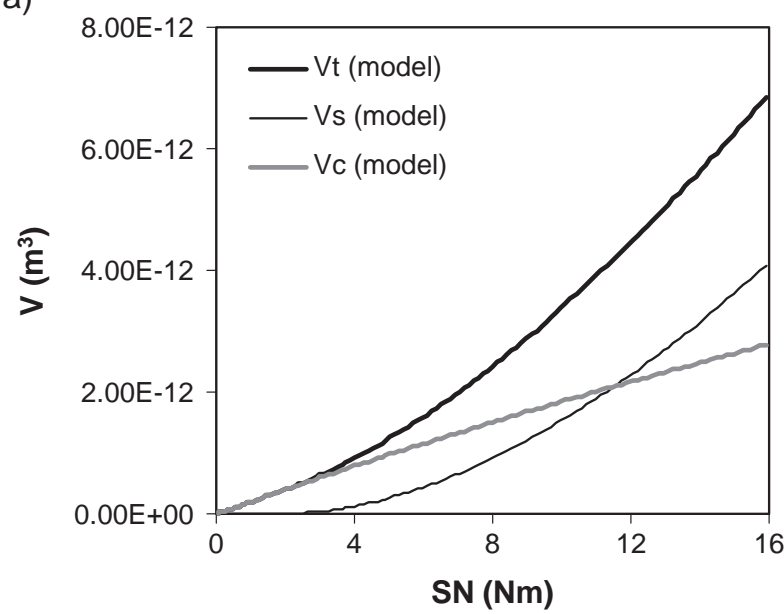

b)

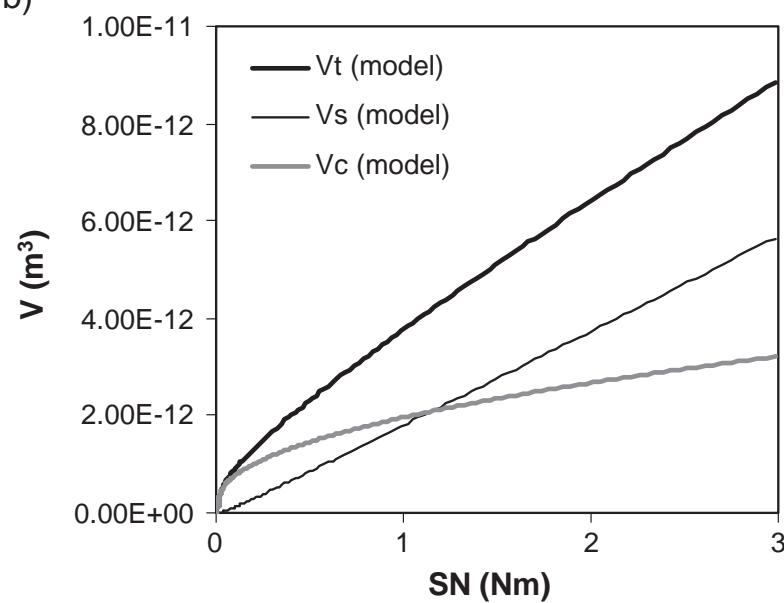

Fig. 3. Examples of modelling results obtained for different conditions Normal load: $0.2 \mathrm{~N}$. (a) $3-\mu \mathrm{m}$ coating with $k_{\mathrm{c}}$ of $2 \times 10^{-13} \mathrm{~m}^{2} / \mathrm{N}$ on a substrate with $k_{\mathrm{s}}$ of $2 \times 10^{-12} \mathrm{~m}^{2} / \mathrm{N}$. (b) $3-\mu \mathrm{m}$ coating with $k_{\mathrm{c}}$ of $2 \times 10^{-11}$ $\mathrm{m}^{2} / \mathrm{N}$ on a substrate with $k_{\mathrm{s}}$ of $2 \times 10^{-12} \mathrm{~m}^{2} / \mathrm{N}$.
(6) increasing the scar depth, $h$, for all practical values of interest, generates new values for $V_{\mathrm{s}}, V_{\mathrm{c}}$ and $V_{\mathrm{t}}$;

(7) when $h>t$, the depth of the scar on the substrate can be calculated as $(h-t)$;

(8) applying Eqs. (1)-(3) the substrate, coating and total wear volume, $V_{\mathrm{s}}, V_{\mathrm{c}}$ and $V_{\mathrm{t}}$ can be found;

(9) the procedure is repeated from 1 to 8 , increasing a step on the wear depth, until the value $h_{\max }$ is reached.

As a result, the wear volumes, $V_{\mathrm{s}}$ and $V_{\mathrm{c}}$, can be substituted in Eq. (6) allowing $S N$ to be calculated. Therefore, the model allows the calculation of the relationships between the $S N$ values and the wearing volumes, and prediction graphs can be drawn. Fig. 3 shows the results obtained by applying the model to two different conditions generated by artificial results. The condition plotted in Fig. 3a corresponds to a $3-\mu \mathrm{m}$ coating that is harder than the substrate, with specific wear rates, respectively, of $2 \times 10^{-13}$ and $2 \times 10^{-12} \mathrm{~m}^{2} / \mathrm{N}$. Assuming a ball diameter of $25.4 \mathrm{~mm}$ and a normal load of $0.2 \mathrm{~N}$, the substrate is reached after 112 rotations and the wear volume of the coating remains greater than the volume removed from the substrate during the first 714 rotations. Considering the same substrate, but for a soft coating with a specific wear rate of $2 \times 10^{-11} \mathrm{~m}^{2} / \mathrm{N}$, the evolution of the results changes significantly as seen in Fig. $3 \mathrm{~b}$. Now, the substrate is reached after only 11 rotations and the wear volume of the substrate becomes greater than the wear volume of the coating after 71 rotations. Thus, for soft coatings, it is very difficult to carry out tests without penetrating the coating thickness completely, and equipment with a very accurate drive system is required.

\section{Experimental work}

In order to validate the prediction model, a micro-scale abrasion study was carried out on thinly coated steels with a fixed-ball type ball cratering equipment. Ball-cratering devices use the rotation of a ball against a coated plane in the presence of an abrasive slurry to produce a circular depression. Two kinds of devices have been used and are classed either free- or fixed-ball types depending on the ball drive system. In free ball equipments, the ball is driven by friction against the rotating shaft and the abrasive slurry is fed into the wearing contact. Since the ball is free and the friction conditions vary, the rotational speed, number of rotations and applied load are all uncertain. In the fixed-ball equipments, the ball is directly connected to the driven shaft, resulting on reliable motion and normal load independently of the friction coefficient.

In our fixed-ball equipment, which was internally developed, the coated specimen is placed in a pivoted holder and the normal load is applied by dead weights. The abrasive slurry, continuously agitated by a magnetic stirrer, is gravity fed onto the rotating ball. The rotational velocity of the ball can be continuously varied. 
Table 1

Coating characteristics

\begin{tabular}{lll}
\hline & TiN coating & Copper coating \\
\hline Substrate & $\begin{array}{l}\text { ASP23 steel, quenched } \\
\text { and tempered to 8500 }\end{array}$ & $\begin{array}{l}\text { M2 steel, quenched } \\
\text { and tempered to } \\
\end{array}$ \\
MPa & $8500 \mathrm{MPa}$ \\
Coating Thickness $(\mu \mathrm{m})$ & 2.5 & 9 \\
$\begin{array}{c}\text { Coating surface } \\
\text { roughness } R_{\mathrm{a}} / R_{\mathrm{z}}(\mu \mathrm{m})\end{array}$ & $0.2 / 2.2$ & $0.25 / 3.5$ \\
\hline
\end{tabular}

A steel ball bearing with $25.4 \mathrm{~mm}$ diameter was used with a normal load of $0.2 \mathrm{~N}$. Two different sputtered coatings were studied: a $2.5-\mu \mathrm{m}$ TiN coating deposited on ASP23 hard tool steel, and a soft copper 9- $\mu \mathrm{m}$ coating on AISI M2 hard tool steel. Table 1 summarises the characteristics of the tested materials. The abrasive medium was a slurry of $\mathrm{SiC}$ particles in distilled water in a concentration of $20 \%$ vol. Because the results were obtained in the scope of different projects, the grain size was slightly different: for the hard TiN coating, an F1200 grade with a median particle size of $4 \mu \mathrm{m}$ was used, and the copper coating was tested with P2500 grade, median size of $8 \mu \mathrm{m}$. The tests were driven at constant rotational speed of $75 \mathrm{rpm}$, corresponding to $0.1 \mathrm{~m} / \mathrm{s}$ tangential speed. To minimize the risk of scattering the results [6], the ball surface was prepared by a run-in procedure prior to the starting of the study.

The number of rotations was selected according to the materials being tested and the test conditions employed. The number of rotations had to be very low for the shortterm tests, to prevent perforation of the surface coating, and thus, allow the specific wear rate of the coating to be calculated by straightway tests. To characterize the substrate materials, some sets of tests have been done on uncoated substrates. The duration of all the tests is given in Table 2.

Before and after testing, the samples were ultrasonically cleaned in acetone to remove all traces of contaminants. Our previous experience has shown that measuring the scar using an optical reflected light microscope is not accurate enough, and thus, a Philips XL30TMP Scanning Electron Microscope (SEM) was used to measure the wear scars in the coating and the substrate, and to observe the morphology of the wear surfaces. An

Table 2

Test duration

\begin{tabular}{|c|c|c|c|c|}
\hline & \multicolumn{2}{|l|}{ TiN coating } & \multicolumn{2}{|c|}{ Copper coating } \\
\hline & $\begin{array}{l}\text { Coated } \\
\text { sample }\end{array}$ & $\begin{array}{l}\text { Uncoated } \\
\text { substrate }\end{array}$ & $\begin{array}{l}\text { Coated } \\
\text { sample }\end{array}$ & $\begin{array}{l}\begin{array}{l}\text { Uncoated } \\
\text { substrate }\end{array} \\
\end{array}$ \\
\hline $\begin{array}{r}\text { Test duration } \\
\text { (rotations) }\end{array}$ & $\begin{array}{l}3,5,10,20, \\
70,150,200, \\
300,400,600, \\
900,1200, \\
1500,2000\end{array}$ & $\begin{array}{l}40,70,100 \\
200,300 \\
400,600\end{array}$ & $\begin{array}{l}1,5,10, \\
15,20,30, \\
50,70,100, \\
150\end{array}$ & $\begin{array}{l}50,100, \\
200,300, \\
400\end{array}$ \\
\hline
\end{tabular}

important advantage of the observation by SEM is the fact that the use of a backscattered detector could be a powerful tool to achieve a better contrast between the coating and the substrate.

\section{Experimental results and discussion}

Some short-term tests were performed to try to obtain low-depth craters without reaching the substrate. For nonperforating tests, the specific wear rate can be calculated by applying the expression $k=V / S N$. Therefore, plotting $V_{\mathrm{c}}$ as a function of $S N$, the specific wear rate of the coating, $k_{\mathrm{c}}$, is the slope of the linear line fitted to the experimental data. For the TiN coating, tests of 3, 5, 10 and 20 rotations gave craters without trough out of the coating and the corresponding specific wear rate was $4.35 \times 10^{-12} \mathrm{~m}^{2} / \mathrm{N}$, Fig. $4 \mathrm{a}$. For copper coating, for test duration of $1,5,10,15$ and 20 rotations, the substrate was not reached, as Fig. 4b shows, and the specific wear rate was $8.1 \times 10^{-12} \mathrm{~m}^{2} / \mathrm{N}$.

In order to validate the model described above, a set of tests has been conducted on each of the uncoated substrates. Because there is no certainty that the behaviour of the

a)
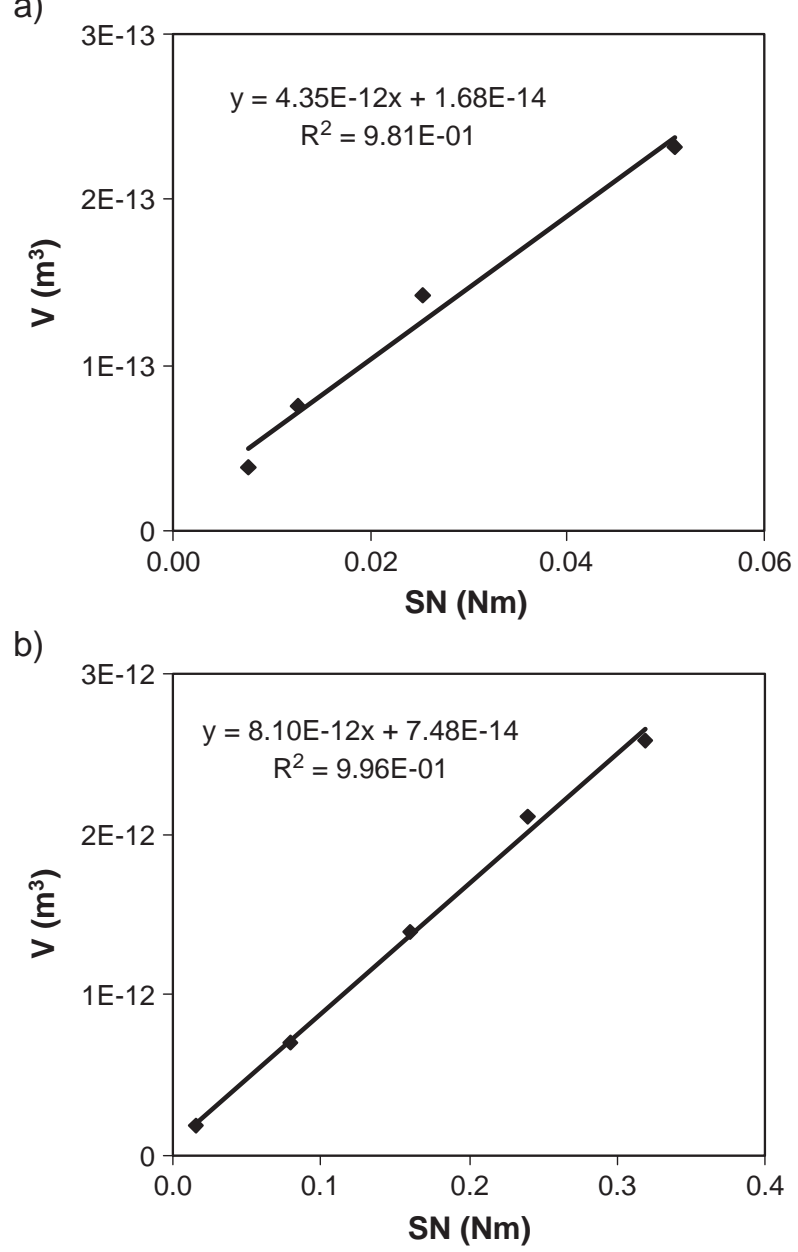

Fig. 4. Non-perforating tests of (a) TiN coating; (b) copper coating. 
a)

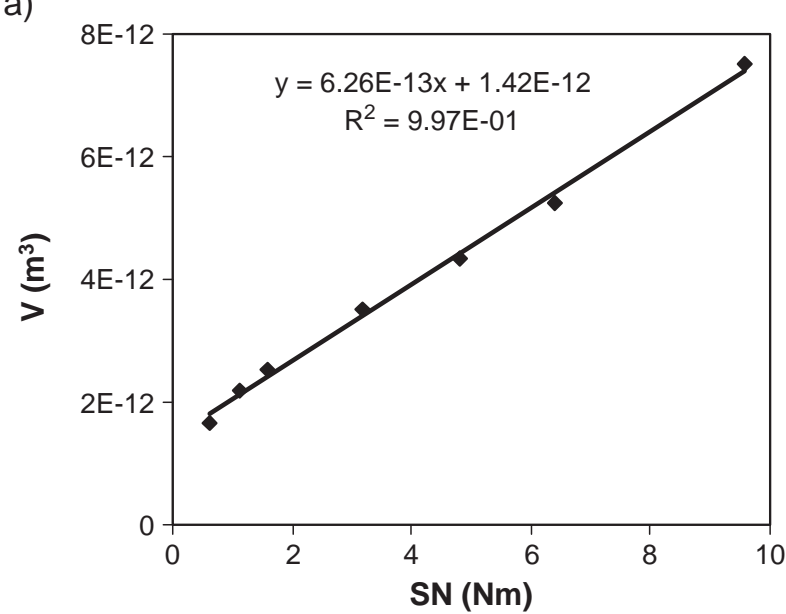

b)

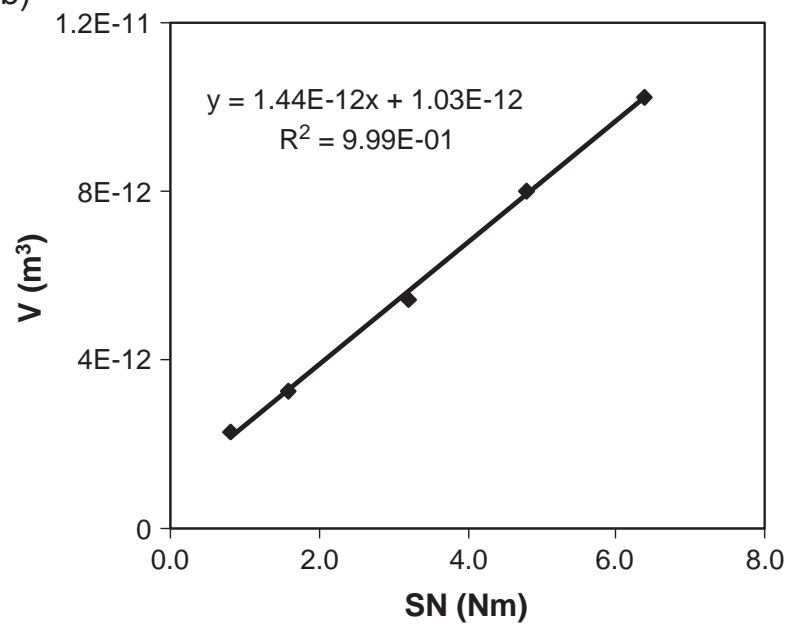

Fig. 5. Micro-scale abrasive tests of uncoated substrates. (a) Quenched and tempered steel ASP23; (b) quenched and tempered steel AISI M2.

substrate evaluated in a separate test is similar to that of the material beneath the tested, even though low-temperature deposition techniques were used to deposit the coatings, the tests to characterize the substrates were performed on the back-uncoated face of the coated specimens. It was thus guaranteed that the mechanical properties of the uncoated tested material were the same as those of the substrate under the coating. The specific wear rates of the uncoated substrates were calculated in the same way as those for the coating. The values obtained were $6.26 \times 10^{-13} \mathrm{~m}^{2} / \mathrm{N}$ for the ASP23 steel, the substrate of the TiN coating, and $1.44 \times 10^{-12} \mathrm{~m}^{2} / \mathrm{N}$ for the M2 steel, the substrate of copper coating (Fig. 5).

A series of perforating tests was carried out on both coatings. In those cases, Eqs. (1) and (2) were used to find the total wear volume and the substrate wear volume, respectively. The volume of the coating removed was calculated by Eq. (3) and, alternatively, by Eq. (5), indicated by $V_{\mathrm{c}}(3)$ and $V_{\mathrm{c}}(5)$. The accuracy of the application of one or the other equation depends mainly on the precision with which the limit of the outer scar diameter is measured. In fact, as shown by Trezona et al. [10], the threshold between the scar and the non-worn surface of the coating is not evident, especially for three-body abrasion wear. Fig. 6a shows the profile of the median diameter of the wear scar for a 1500 rotation test on a TiN specimen. The circle arc fitted the profile has a radius of $12.68 \mathrm{~mm}$, confirming the validity of the assumption that the crater has a radius similar to the ball. The correct position of the outer limits, points A and $\mathrm{B}$, is very difficult to discern, especially with a reflective light optical microscope. The inner diameter, corresponding to the limit between the coating and the substrate (line 2 in Fig. 6b), is usually much more accurate than the outer limit (line 1 in Fig. 6b). When Eq. (5) was used, the thicknesses of both coatings were determined in separate abrasion tests, using a $1-\mu \mathrm{m}$ diamond slurry. In these tests, the wear occurs by two-body abrasion, leading to much better defined craters (Fig. 7).

From the results of perforating tests, the Allsop method [9] was used to calculate the specific wear rate for both coating and substrate. The coating wear volume was calculated with Eq. (5) and the method described by Kusano et al. was employed [8]. In this method, a linear plot of $S N /$

a)

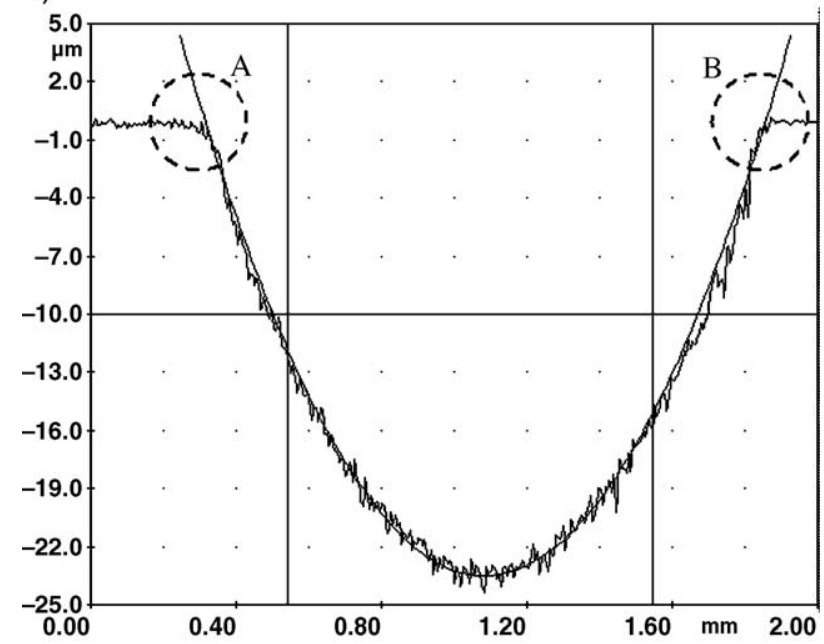

b)

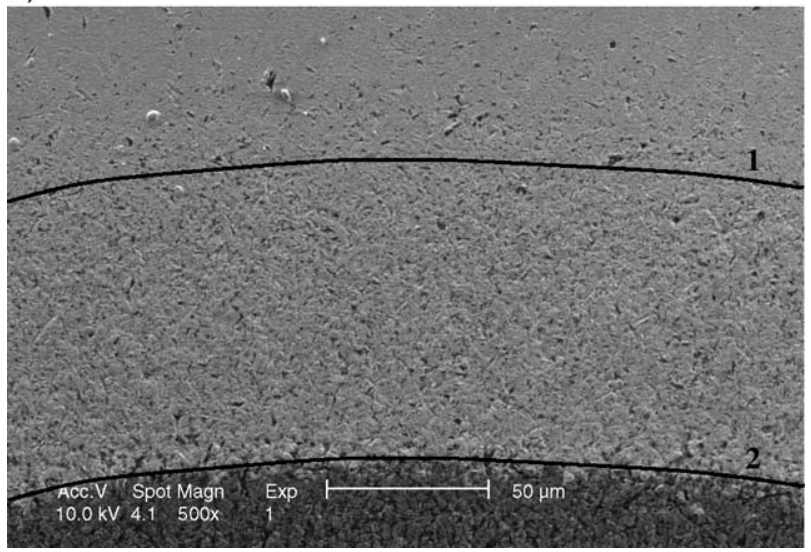

Fig. 6. Profile of the median diameter of an abrasion scar (a) and SEM micrograph (b) (TiN, 1500 rotations). 


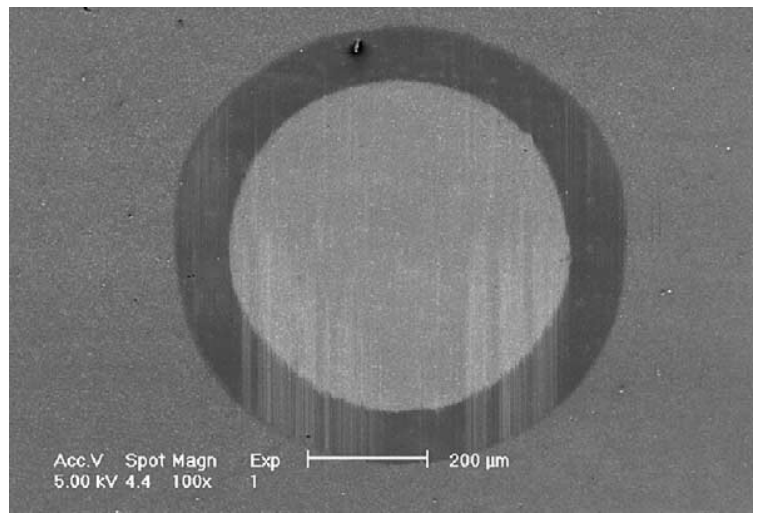

Fig. 7. Scar of a perforating test on TiN coating using a $1-\mu \mathrm{m}$ diamond slurry.

$V_{\mathrm{c}}$ against $V_{\mathrm{c}} / V_{\mathrm{s}}$ can be obtained from the set of experimental data (Fig. 8). According to Eq. (7), the inverses of the intercept and of the slope of the linear line fitted to the experimental data correspond to the specific wear rate of the substrate and the coating, respectively. Using the square-minimum linear fit lines shown in the plots
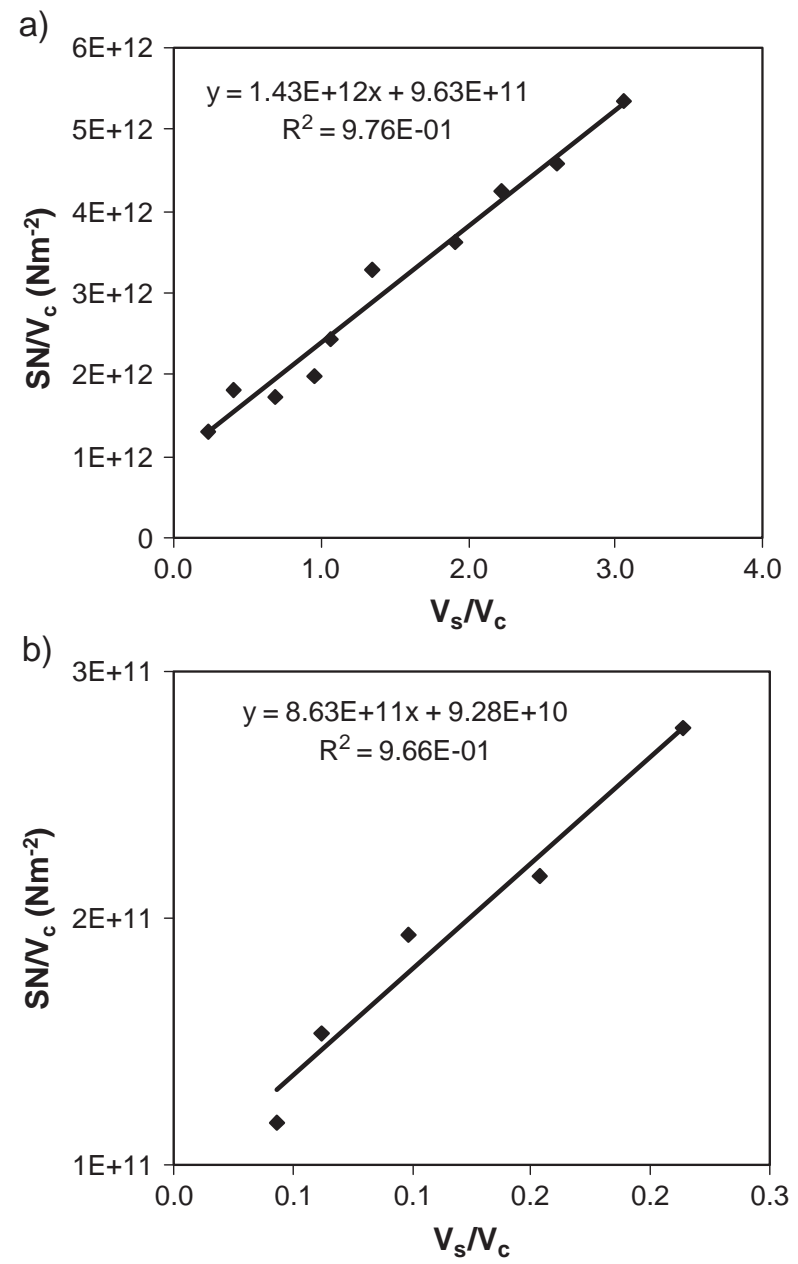

Fig. 8. Linear plot of $S N / V_{\mathrm{c}}$ against $V_{\mathrm{s}} / V_{\mathrm{c}}$ to apply the Allsop analysis method [4]. (a) TiN coating; (b) copper coating.
Table 3

Comparison of specific wear rates obtained from perforating and nonperforating tests

\begin{tabular}{|c|c|c|c|c|}
\hline & \multicolumn{4}{|l|}{$k\left[\mathrm{~m}^{2} / \mathrm{N}\right]$} \\
\hline & \multicolumn{2}{|l|}{ TiN coating } & \multicolumn{2}{|c|}{ Copper coating } \\
\hline & Coating & Substrate & Coating & Substrate \\
\hline $\begin{array}{c}\text { Perforating } \\
\text { tests (1) }\end{array}$ & $1.04 \times 10^{-12}$ & $6.99 \times 10^{-13}$ & $1.08 \times 10^{-11}$ & $1.16 \times 10^{-1}$ \\
\hline $\begin{array}{l}\text { Non-perforating } \\
\text { tests (2) }\end{array}$ & $4.35 \times 10^{-12}$ & $6.26 \times 10^{-13}$ & $8.1 \times 10^{-12}$ & $1.44 \times 10^{-1}$ \\
\hline$\Delta k[\%]$ & -76 & +12 & +33 & -19 \\
\hline
\end{tabular}

of Fig. 8, the specific wear rates of the substrate and of the coating can be calculated for both tested coatings (Table 3 ).

As Table 3 shows, in some cases there is a significant difference between the specific wear rates obtained by the results of the perforating tests, simultaneously giving the behaviour of the substrate and the coating, and those yielded by non-perforating tests, conducted separately on the coating and the uncoated substrate. The biggest disparity occurs for the TiN coating, with a difference of $76 \%$ between the two methods. Kusano et al. [8] has simulated the errors of the method used to separate the coating and specific wear rate for several $k_{\mathrm{c}} / k_{\mathrm{S}}$ values, and the relative errors are very small when compared to the

a)

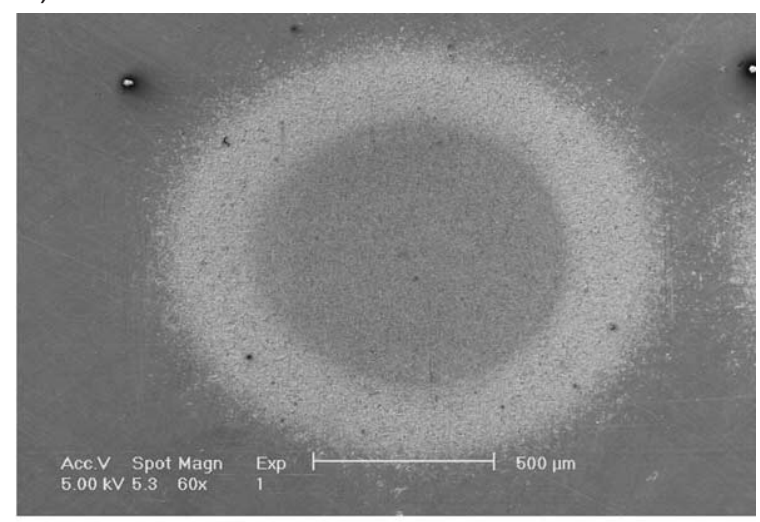

b)

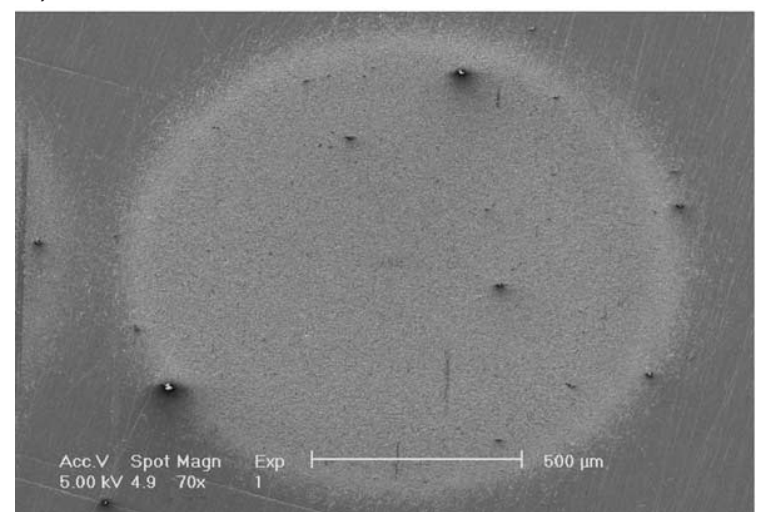

Fig. 9. Wear scars of micro-scale abrasive tests. (a) Copper coating, 100 rotations. (b) Uncoated ASP23, 400 rotations. 
differences shown in Table 3. It seems, therefore, that it is difficult to compare the results obtained from the perforating tests and the non-perforating tests, although the wear mechanism is three-body abrasion in all cases, as shown in the micrograph of the morphology of coated and uncoated scars (Fig. 9). The scatter of the results depends mainly on the measurement errors of the crater's outer diameter. As previously explained, the outer limit of the crater shows a tenuous halo that makes their accurate measurement difficult. The inaccuracy of the volume estimation is inversely proportional to the crater diameter and consequently is bigger in the beginning of the test. This fact justifies some unexpected values achieved in the scope of this work, namely, the non-zero intercepts on the linear evolutions of Figs. 4 and 5 and the difference between the specific wear rates when calculated from perforating and non-perforating tests (Table 3).

In spite of the above differences, if we try to apply the model previously derived, the wear volumes measured in experimental tests fit very well with those predicted (Fig.

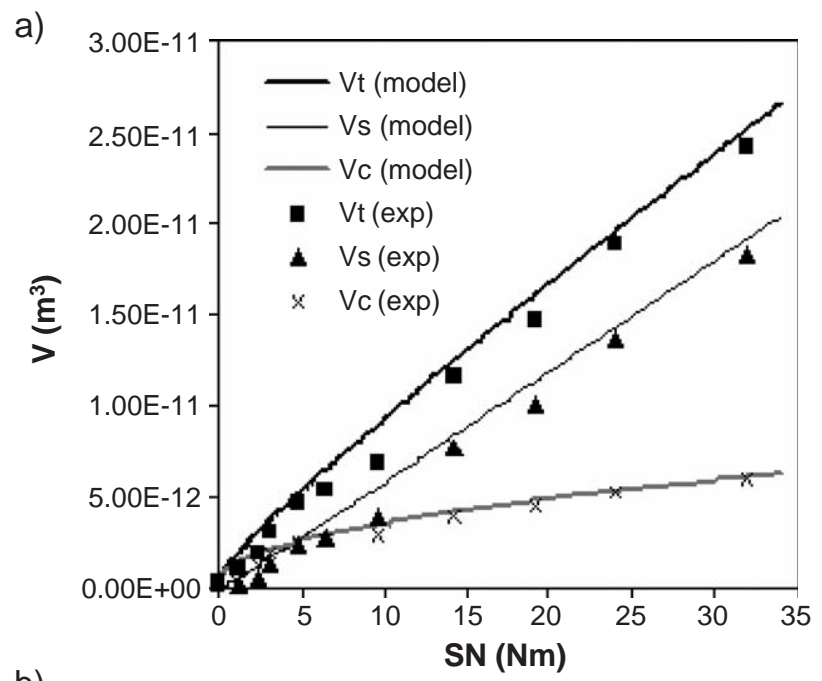

b)

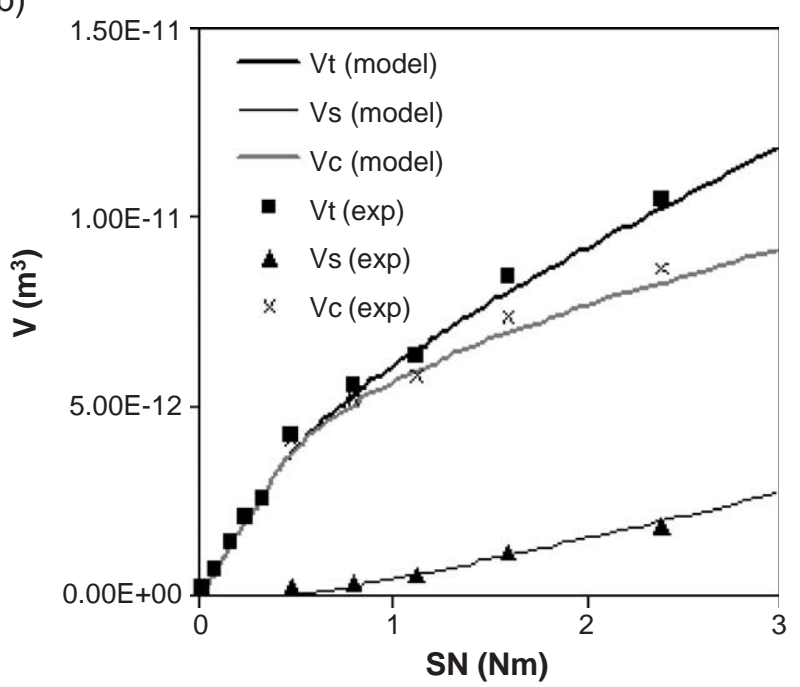

Fig. 10. Comparison of the results of the prediction model with the experimental data. (a) TiN coating; (b) copper coating.

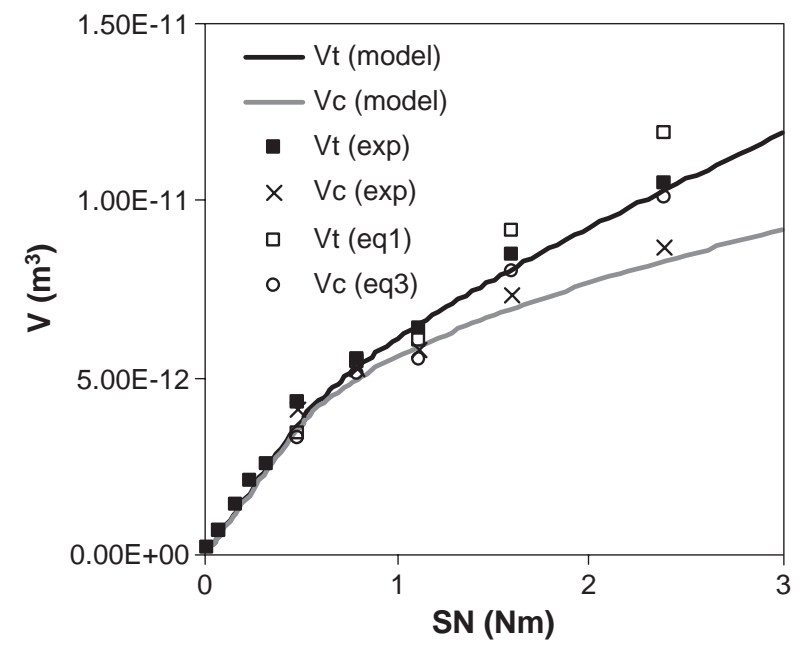

Fig. 11. Comparison of the prediction model with the experimental data for the copper coating, when applying Eqs. (3) and (5).

10). The model thus seems to be a good tool for analysing contacts with throughout all the coating thickness and it can be even used as a design procedure for coated surfaces when a composite contact (involving the coating and the substrate) is expected. As shown in Fig. 10, the model can be used to forecast both the first period, when the coating has not yet been perforated, and the second period, when the contact involves a mixture of both coating and substrate.

The method is sufficiently accurate to ascertain the best approach to calculating the total and the coating wear volume (Fig. 11). In fact, for the thicker copper coating, it is evident that Eq. (5) leads to better results than Eq. (3). The wear volume of the coating, $V_{c}$, and the total volume $V_{\mathrm{t}}$, calculated by Eq. (5), fits better with the prediction than Eq. (3).

\section{Conclusions}

The suitability of a prediction model for characterising the wear behaviour of thinly coated surfaces, based on the specific wear rates of the coating and of the substrate, determined separately in previous tests, has been presented and discussed.

The model developed uses the imposed shape principle usually assumed for this kind of test.

In spite of some imprecision on the wear volume, which depends mainly on the measurement errors of the crater's outer diameter, the results forecasted by the model agree well with experimental results both for hard and soft coatings.

The prediction model seems to be a promising tool for analysing contacts with throughout of all the coating thickness and it can even be used as a design procedure for coated surfaces when a composite contact (involving the coating and the substrate) is expected. 


\section{Nomenclature}

$a$ diameter of the crater measured in the interface coating/ substrate

$b$ diameter of the crater measured in the surface of the coating

$h, h_{\max }, \Delta h$ wear depth, maximum value, step

$k_{\mathrm{c}} \quad$ specific wear rate of the coating $\left(\mathrm{m}^{2} / \mathrm{N}\right)$

$k_{\mathrm{s}} \quad$ specific wear rate of the substrate $\left(\mathrm{m}^{2} / \mathrm{N}\right)$

$N \quad$ normal load

$R \quad$ radius of the ball

$S \quad$ sliding distance is the distance travelled by the ball over the specimen $(\mathrm{m})$

SN $\quad$ sliding distance $\times$ normal load (parameter proportional to the energy dissipated in the contact) $(\mathrm{N} \mathrm{m})$

$t \quad$ coating thickness

$V_{\mathrm{c}} \quad$ fraction of the crater volume corresponding to the coating $\left(\mathrm{m}^{3}\right)$

$V_{\mathrm{s}} \quad$ fraction of the crater volume corresponding to the substrate $\left(\mathrm{m}^{3}\right)$

$V_{\mathrm{t}} \quad$ volume of the entire crater produced by wear $\left(\mathrm{m}^{3}\right)$

\section{Acknowledgements}

This work was done under a project funded by the Portuguese Foundation for Science and Technology (POCTI/33710/EME/2000).

\section{References}

[1] Asa Kassman, Staffan Jacobson, Lynn Erickson, Per Hedenqvist, Mikael Olsson, Surf. Coat. Technol. 50 (1991) 75.

[2] N. Axén, S. Jacobson, S. Hogmark, Trib. Int. 27 (4) (1994) 233.

[3] K.L. Rutherford, I.M. Hutchings, Surf. Coat. Technol. 79 (1996) 231.

[4] K.L. Rutherford, I.M. Hutchings, J. Test. Eval. 25 (2) (1997) 250.

[5] N. Axén, S. Jacobson, S. Hogmark, Wear 203-204 (1997) 637.

[6] D.N. Allsop, R.I. Trezona, I.M. Hutchings, Trib. Lett. 5 (1998) 259.

[7] A. Ramalho, Trib. Lett. 16 (1) (2004) 133.

[8] Y. Kusano, K. Van Acker, I.M. Hutchings, Surf. Coat. Technol. 183 (2004) 312.

[9] D.N. Allsop, Abrasive Wear of Bulk Materials and Hard Coatings, $\mathrm{PhD}$ thesis, University of Cambridge, 1999.

[10] R.I. Trezona, I.M. Hutchings, Wear 233-235 (1999) 209. 